\title{
Li-salt functionalised carbon nanotubes as low work function field emitters
}

\author{
Stephen M. Lyth*, R. A. Hatton and S. R. P. Silva \\ Advanced Technology Institute \\ University of Surrey \\ Guildford, Surrey, UK \\ *s.lyth@surrey.ac.uk \\ Telephone: +44 1481 686083, Fax: +44 1483689404
}

\section{Introduction}

Carbon nanotubes have excellent field emission (FE) properties. $^{1-3}$ The work function (WF) of materials plays a crucial role in their FE properties. From the well known Fowler-Nordheim equation, ${ }^{4}$ it is evident that reducing the WF should result in an exponential increase in current density at a given electric field. Therefore, for cold cathode applications it is desirable to minimize the emitter WF without compromising the cathode stability towards oxidation. We have recently shown that the WF of acid-oxidized multiwall carbon nanotubes (o-MWNT) can be reduced by exchanging acidic surface groups with alkali metal cations. ${ }^{5}$ We report a method for applying o-MWNT onto carbon fibre (CF) fabric from solution and an improvement in the $\mathrm{FE}$ properties after converting carboxylic groups to the carboxylate salt of lithium via cation exchange. It is envisaged that this technique could be applied to a wide range of nanotube emitters to reduce the $\mathrm{WF}$ and improve the FE properties.

\section{Experimental}

A stable aqueous dispersion was formed by refluxing nanotubes in a concentrated nitric and sulphuric acid mixture, resulting in the formation of carboxylic acid groups attached to the nanotube surface. These interact with water molecules via H-bonding and an o-MWNT ink was formed. The alkali cation exchange (Fig. 1) was achieved by dispersing $\mathrm{LiOH}$ in the o-MWNT ink, thoroughly mixing in an ultrasonic bath, filtering and then washing with pure water, ensuring the removal of excess $\mathrm{LiOH}$ and resulting in a lithiumfunctionalized ink $\left(\mathrm{Li}^{+} \mathrm{MWNT}\right)$. The $\mathrm{CF}$ fabric was hydrophobic, so it was subject to a microwave oxygen plasma treatment. This partially oxidizes the CF surface, creating oxygen containing moieties, which enable H-bonding. Additionally, H-bonding results in strong adhesion between the CF and the o-MWNT layer. The plasma-treated CF was dipped in o-MWNT and $\mathrm{Li}^{+} \mathrm{MWNT}$, removed and baked to remove residual water.

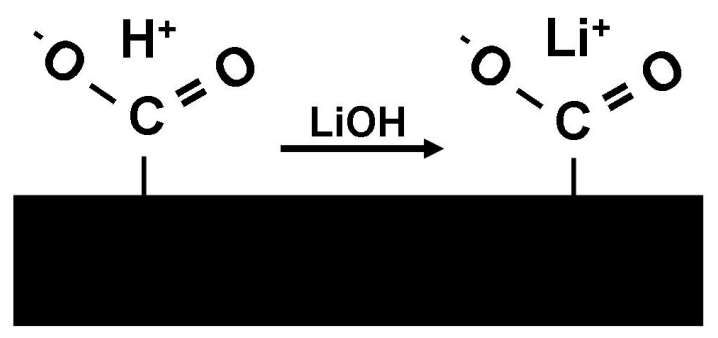

Fig. 1: Schematic of the cation exchange process.

\section{Results}

Figure 2 shows SEMs of the substrates. Fig. 2(a) shows the pristine CF. Fig. 2(b) shows the CF after oxygen plasma treatment. Fig. 2(c) and 2(d) show the CF after o-MWNT coating (the $\mathrm{Li}^{+} \mathrm{MWNT}$ layer was identical) with a uniform layer across the whole $\mathrm{CF}$ surface.

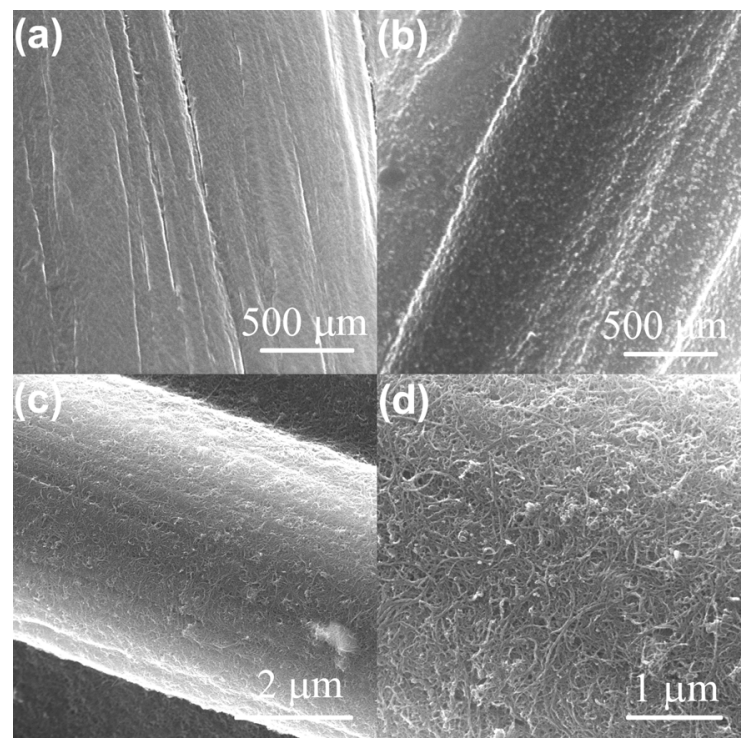

Fig. 2: SEM images of the substrates. 
The FE properties were investigated in a diode configuration with a spherical stainless-steel anode. The threshold field $\left(\mathrm{E}_{\mathrm{th}}\right)$ was defined as the macroscopic electric field (E) at which $1 \mathrm{nA}$ was detected. Figure 3 shows the FE current as a function of $\mathrm{E}$ for four different $\mathrm{CF}$ fabric samples. The pristine CF fabric had $\mathrm{E}_{\mathrm{th}}=0.42 \mathrm{~V} / \mu \mathrm{m}$. After oxygen plasma treatment, $\mathrm{E}_{\mathrm{th}}=0.58 \mathrm{~V} / \mu \mathrm{m}$. This increase in $\mathrm{E}_{\text {th }}$ can be attributed to the increase in the WF of the CF after plasma treatment to $\sim 4.8$ $\mathrm{eV}{ }^{6}$

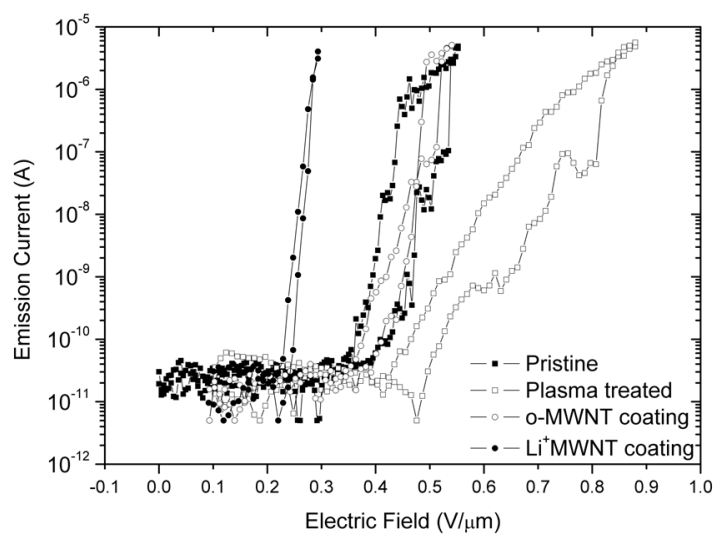

Fig. 3: Emission current-field curves for the samples.

Coating the plasma treated CF with o-MWNT results in $\mathrm{E}_{\text {th }}=0.42 \mathrm{~V} / \mu \mathrm{m}$. This reduction in $\mathrm{E}_{\text {th }}$ compared with the plasma treated CF is attributed to the modification of the surface geometry of the fibres by the o-MWNT, resulting in an overall increase in geometric field enhancement $(\beta)$ and therefore a higher local field at the emitting sites. However, since the WF of o-MWNT $(5.0 \mathrm{eV})^{5}$ is larger that that of the pristine $\mathrm{CF}(4.4 \mathrm{eV})$, the beneficial effect of $\beta$ is offset by the increase in WF.

Coating the CF fabric with $\mathrm{Li}^{+} \mathrm{MWNT}$ results in $\mathrm{E}_{\mathrm{th}}=0.25 \mathrm{~V} / \mu \mathrm{m}$. This improvement is attributed to the lowering in $\mathrm{WF}$ from $5.0 \mathrm{eV}$ to $4.6 \mathrm{eV}{ }^{6} \mathrm{In}$ this case, the extremely low error suggests that there is very little variation in emission properties across the entire surface which is greater than 1 $\mathrm{cm}^{2}$. It should also be noted that the hysteresis for the $\mathrm{Li}^{+} \mathrm{MWNT}$ coated samples is exceptionally low, indicative of the stability of the emitter during FE. These results are summarised in Table 1.

\begin{tabular}{lcccc}
\hline \hline & $\begin{array}{c}\mathrm{E}_{\text {th }} \\
(\mathrm{V} / \mu \mathrm{m})\end{array}$ & $\begin{array}{c}\text { Error } \\
(\mathrm{V} / \mu \mathrm{m})\end{array}$ & $\begin{array}{c}\text { Hysteresis } \\
(\mathrm{V} / \mu \mathrm{m})\end{array}$ & $\begin{array}{c}\text { Work } \\
\text { function } \\
(\mathrm{eV})\end{array}$ \\
\hline $\begin{array}{l}\text { Pristine } \\
\text { carbon fibre }\end{array}$ & $\mathbf{0 . 4 2}$ & $\pm \mathbf{0 . 0 3}$ & $\mathbf{0 . 2 0}$ & $\mathbf{4 . 4}{ }^{[6]}$ \\
$\begin{array}{l}\text { Plasma } \\
\text { treated fibre }\end{array}$ & $\mathbf{0 . 5 8}$ & $\pm \mathbf{0 . 1 5}$ & $\mathbf{0 . 2 3}$ & $\mathbf{4 . 8}{ }^{[6]}$ \\
$\begin{array}{l}\text { o-MWNT } \\
\text { coated fibre }\end{array}$ & $\mathbf{0 . 4 2}$ & $\pm \mathbf{0 . 0 9}$ & $\mathbf{0 . 0 8}$ & $\mathbf{5 . 1}$ \\
$\begin{array}{l}\text { Li }^{+} \mathrm{MWNT} \\
\text { coated fibre }\end{array}$ & $\mathbf{0 . 2 5}$ & $\pm \mathbf{0 . 0 2}$ & $\mathbf{0 . 0 4}$ & $\mathbf{4 . 6}$ \\
\hline
\end{tabular}

Table 1: Summary of numerical results.

\section{Conclusion}

In summary, CF fabric was surface oxidized, dip coated in o-MWNT and $\mathrm{Li}^{+} \mathrm{MWNT}$, and the FE properties investigated. The threshold field was observed to vary depending on the process applied to the $\mathrm{CF}$ fabric, ultimately leading to a substantial reduction in $\mathrm{E}_{\text {th }}$ from $0.42 \mathrm{~V} / \mu \mathrm{m}$ for oMWNT to $0.25 \mathrm{~V} / \mu \mathrm{m}$, for $\mathrm{Li}^{+} \mathrm{MWNT}$. This marked reduction in $E_{\text {th }}$ is attributed to the reduction in work function from $5.0 \mathrm{eV}$ to $4.6 \mathrm{eV}$. An associated decrease in hysteresis and an increase in emission uniformity across the sample were also observed. This method provides a simple, cheap and scalable manner in which to create high performance, large area and widely applicable field emitting electrodes.

We would like to thank EPSRC (UK) for funding this research via the $\mathrm{CBE}$ and Portfolio Partnership programmes.

\section{References}

1. A. G. Rinzler, et al. Science 269, 1550 (1995)

2. W. A. Deheer, et al. Science 270, 1179 (1995)

3. S. M. Lyth et al. APL 90, 013120 (2007)

4. R. H. Fowler et al. Proc. Roy. Soc. Ser. A 119, 173 (1928)

5. N. P. Blanchard et al. CPL 434, 92 (2007)

6. H. Ago et al. Phys. Chem. B 103, 8116 (1999) 